\title{
Glocalização interativa, dromocracia informacional e espaço urbano: smart cities como último refúgio do imaginário tecnoutópico contemporâneo
}

\author{
Eugênio Trivinho' \\ https://orcid.org/0000-0001-8764-3700 \\ I - PUC-SP. \\ São Paulo (SP), Brasil
}

Resumo: O presente texto está dedicado à compreensão da significação social-histórica das smart cities no profuso rastro do imaginário tecnoutópico ocidental. A política da argumentação é flexionada por três movimentos cumulativos, assim dispostos: primeiro, as smart cities são inseridas no quadro da epistemologia crítica da glocalização mundial e de sua dinâmica informacional em tempo real; segundo, as smart cities são apreendidas no arco recente de um profundo deslocamento de padrões imaginários utópicos tradicionais em favor de tecnoteleologias emergentes, vinculadas aos media digitais e às redes interativas; e, terceiro, são mobilizados fundamentos necessários para caracterizar as smart cities como última fulgurante configuração do mencionado imaginário tecnoutópico.

Palavras-chave: civilização mediática; imaginário tecnoutópico; dromocracia informacional; smart cities; Grande Glocal.

Abstract: Interactive glocalization, informational dromocracy and urban space: smart cities as the refuge of the contemporary techno-utopic imaginary - The article approaches the sociohistorical significance of smart cities in the extensive track of the western techno-utopic imaginary. The argumentation policy operates three cumulative movements, as follows: first, it inserts smart cities in the framework of the critical epistemology of the worldwide glocalization and its informational dynamics in real-time; second, it apprehends smart cities in the recent arc of a profound displacement of traditional utopian imaginary patterns in favor of emerging techno-teleologies, linked to digital media and interactive networks; and, third, it mobilizes all necessary fundamentals to characterize smart cities as the last refulgent configuration of the aforementioned techno-utopic imaginary.

Keywords: media civilization; techno-utopic imaginary; informational dromocracy; smart cities; Grande Glocal. 


\section{Nota introdutória}

Desde pelo menos o início deste século, as chamadas smart cities [cidades "inteligentes", em tradução corrente] vêm sendo objeto de reflexão acadêmica, preocupação de Estados locais e/ou investimentos megacorporativos no mundo inteiro, sob os mais diferentes prismas, interesses e expectativas. Ao que tudo indica - e sobretudo porque a ideia matricial aí subsumida costuma se apresentar com significantes distintos -, a discussão sobre o que significam "espaços urbanos" tecnologicamente aperfeiçoados tende a cauda longa, em virtude do potencial de espalhamento global demonstrado por macroprojetos sociais dessa natureza.

Recobra muito pouco esforço dedutivo alcançar a fleuma predominante da miríade dessa produção especializada: a quase totalidade das posições e opiniões - institucionalgovernamentais, corporativo-industriais e teórico-pragmáticas - que esculpem a matéria dança sob trilha sonora há muito conhecida: respira, nesse contexto, a tônica do ciberufanismo. A questão das smart cities se encontra eivada dessa tendência de cariz inconsciente sobre suas próprias consequências, e isto não deixa de causar perplexidade a quem, com um pé na história, outro na interpretação, mantém diâmetro de visão mais alargado e de maior profundidade a respeito.

$\mathrm{Na}$ contramão dessa crespa espiral de ausência de tensão com os horizontes da civilização tecnológica em curso (multimediática, sob tempo instantâneo e fincada em bases multicapitalistas mundializadas) e que sói sinalizar à crítica o aterro mais próximo da inutilidade e/ou do direito à existência, cuida-se, neste estudo, da tensão teórica em relação ao lugar que as smart cities ocupam no imaginário tecnológico ocidental - uma crítica, portanto, de perfil socialmente orientado, tão rigorosamente convicto quanto hoje mais confluentes se autodemonstram os discursos e práticas ciberufanistas.1

O empreendimento teórico propende para a compreensão da significação socialhistórica das smart cities, especialmente no estirão avançado da mencionada tendência civilizatória, cerzida, na imanência, pela apropriação e usos diuturnos de tecnologias de comunicação em tempo real, no condão cultural - inteiramente desalfandegado - que se estende da esfera do trabalho à do tempo livre e de lazer. Trata-se de uma significação especial - aquela que diz respeito ao papel estrutural (e também às consequências) que as smart cities jogam no estrato simbólico e imaginário do social na cultura ocidental, com interesse exclusivamente focado na inserção desse tipo de conformação citadina no quadro das configurações utópicas dessa história mais recente. As smart cities - aleguese, de partida, diversificando a ênfase - reescrevem a dimensão material, simbólica e

1 A argumentação se subordina à episteme desenvolvida pelo autor em mais de vinte anos de pesquisas teóricas, a maioria das quais apoiada pelo CNPq (Bolsa de Produtividade em Pesquisa). O texto foi consolidado sob convênio internacional de cooperação acadêmica com a Universidade de Bologna (UNIBO). Suas bases preliminares foram apresentadas no XV Congresso IBERCOM, realizado na Universidade Católica Portuguesa (UCP), em Lisboa, em 2017. Ambos os momentos - apresentação e redação - receberam importante esteio do PIPEq - Plano de Incentivo à Pesquisa da PUC-SP. 
imaginária das narrativas teleológicas tradicionais (cf. LYOTARD, 1986, 1993), sobretudo as legadas pelos séculos XVIII e XIX.

O transcurso da reflexão - destinado senão a responder, ao seu modo, à indagação "o que são realmente smart cities?" - concentra tanto as características essenciais quanto, mais fundamentalmente, os pressupostos de base da existência em bloco dessas conformações citadinas, par de fatoração quase sempre olvidado e igualmente invisibilizado no panteão perceptivo de maior especialização.

\section{Smart cities conforme a sua empiria}

As smart cities constituem projetos e práticas de Estado e/ou de governos locais, em prefeituras, e/ou de grandes corporações, com a participação de ONGs e do terceiro setor, que visam, geralmente (mas não necessariamente), com base em tecnologias digitais em tempo real e com a participação individual e grupal ativa de cidadãos, garantir bem-estar social - mesmo se na lógica discursiva vaga de "uma vida melhor" - mediante criação, distribuição e circulação mais eficiente dos resultados do conhecimento tecnocientífico e, bem assim, da informação instantânea [articulada em GPS (Global Positioning System)] como recurso estratégico fundamental. Tais projetos e práticas são atualmente encontrados, em escalas, intensidades e consequências variáveis, em inúmeras metrópoles e importantes cidades do mundo. Proliferam também, de modo autônomo, em áreas distintas de necessidades humanas patentes: saúde, educação, fornecimento de energia, abastecimento de água, saneamento básico, limpeza urbana, coleta de lixo, hidratação de jardins, assistência a estacionamento de veículos, segurança pública e assim por diante.

\subsection{Pressupostos de base das smart cities}

Para além de diferenças marcantemente idiossincráticas, há fio condutor genérico e múltiplo, tão concreto quanto ocluso, a perpassar e perfilar as smart cities, trate-se de projetos dessa natureza no Brasil (Curitiba e Rio de Janeiro, por exemplo) ou nos Estados Unidos, na Espanha ou na Suécia, na Finlândia ou em Dubai, para mencionar apenas esta seleta de países desenvolvidos e emergentes.

Dentre os traços estruturais das smart cities, subsumidos nesse fio condutor, podemse, por certo, encontrar (a) a revitalização radical da social engineering norte-americana, na espécie de um funcionamento otimizado do social; (b) a renovação do empirismo tecnológico transposto para a vida cotidiana, agora na modalidade de uma vivência prática mais eficaz em resultados, na menor unidade de tempo; (c) o pragmatismo produtivista da cidadania, tornado mais eficiente com o uso de tecnologias digitais e interativas (o que se integra com a participação recorrente de pessoas, sobretudo individualmente, em compasso colaborativo); e (d) o ideal especular de uma vida coletiva plena, fluente e, 
no quanto possível, harmônica, vencida - pretensamente - a legitimidade da discussão [para todos os efeitos, ainda aberta] sobre a automação "desempregatícia", outro traço relevante.

No que interessa à presente reflexão, não obstante, as smart cities, do ponto de vista de sua construção social-histórica² e de sua inserção no rol utópico do imaginário sociotecnológico, envolvem três pontos fundamentais, conforme abaixo.

a. As smart cities são, paradoxalmente, da ordem do tempo, menos da ordem do espaço. O argumento, que pode soar herético (e provocativo) a todas as visões cartesiano-objetivistas e funcionalista-empiristas, erigidas em boa equidistância com a fenomenologia (de Husserl a Merleau-Ponty) e, em especial, com a sociodromologia fenomenológica (de Virilio), procede inteiramente. A eficácia (do sentido) da "inteligência" implicada nos macroprojetos de smart cities diz respeito - conforme sinalizado acima - ao alcance de resultados práticos e efetivos (quaisquer que sejam eles) no menor lastro temporal. Trata-se, também nesse aspecto, de alto índice de produtivismo na escala de configuração do edifício citadino, pressionada a catapultar-se a uma modernização infraestrutural conforme a natureza matricial-tecnológica das forças produtivas de época. A ocupação da geografia, do espaço territorial, da conformação urbana, de todas as territorialidades construídas enfim, faz-se dominantemente por essa via, a da temporalização instantânea das práticas sociais (mediadas ou não por máquinas), tendo em vista a vigência ampliada e irreversível da velocidade tecnológica, socialmente materializada pelas várias formas de apropriação e uso cotidianos de equipamentos de informação e comunicação em tempo real.

b. A temporalização sociotecnológica das smart cities - em outras palavras, o processo de intensa dromocratização que as articula (conforme item subsequente) - constitui chave basilar de leitura que permite, em reverso, apreender tais formações citadinas com esteio em dois processos estruturais atuais: sua autoconstrução une, de modo inextricável, o local em que o corpo de cada sujeito se encontra e o global representativo da massa de conteúdos circulantes nas redes - numa palavra, as smart cities são produto histórico do desenvolvimento do processo de glocalização planetária -, para além do local e do global, como instâncias divorciadas ou pouco interconectadas. O fenômeno glocal, cuja efetividade internamente múltipla repercute na forma social do mencionado processo de glocalização, equivale a empiria processual cativa do século XX. Desde, pelo menos, meados desse século, o presente importa frisar - não se assenta mais exclusivamente nem no reduto local nem

2 A noção de "social-histórico", atinente à macroescala sociocultural e histórico-antropológica (política lato sensu) do hic et nunc - o presente instituído, em curso contínuo e em tensão com o não-identitário -, com reverberações civilizatórias, projetadas sobre o futuro mediato, é inspirada em Castoriadis (1982). 
na dimensão global da realidade cotidiana, abrigados na perspectiva acima, como franjas disjuntas ou paralelas. Vive-se a hibridação de, entre e a partir de ambos, sem redução a qualquer deles, no universo multimediático da informação. Invenção tecnocultural típica do capitalismo industrial e pósindustrial - e, não por acaso, macrovetor irreversível de seu reescalonamento social-histórico para além do velho mundo ocidental -, o fenômeno glocal se sofistica e se expande às últimas consequências no próspero caudal dos media de massa, interativos ou híbridos capazes de tempo real. Seu braço sociotecnológico tardio são os media digitais e as redes interativas.

c. Inexistem smart cities desenvolvidas que prescindam da glocalização interativa, seu pressuposto infraestrutural e processual sine qua non. A dependência umbilical de invenções atinentes à cadeia industrial desses media e redes autodemonstra que as smart cities são, portanto, uma protuberância urbanomediática da tecnociência da comunicação satelitizada. Acaso reinasse nas últimas três décadas o vácuo dessa comunicação eletrônica, as smart cities jamais o seriam - ao menos, tais como no talhe especificado acima.

d. O processo de glocalização, por sua vez, revela - vale enfatizá-lo, na metáfora a vigência da velocidade na cimentação das vigas-mestras (do primeiro ao último patamar de construção) das smart cities. A matéria concerne, simultânea e complementarmente, à noção de dromocratização informacional, processo que caracteriza uma condição macroestrutural de articulação matricial, autopoiética e cabal da vida urbana contemporânea (no que tange à sua tendência majoritária, fincada no mercado das trocas) pela velocidade típica da transmissão digital (online e streaming, vencidos há tempos o rádio e a TV, live) e, em particular, pela informação, seja como unidade sígnica irredutível diuturnamente construtora de mundo (ao invés de ser dele apenas elemento de "representação"), seja como motor da dinâmica epocal da vida social [na perspectiva de Virilio (1996, p. 116-134)]. Essa questão evoca, em espelho retroativo, a predominância do vetor do tempo sobre o vetor do espaço, a da velocidade sobre o território, a da aceleração de todos os processos sobre a geografia, a da informação satelitizada e instantânea sobre a urbis [aqui tomada em sentido tradicional, atinente a dinâmica social vívida, porém exclusivamente local (não glocal)] sobredeterminações e/ou inversões que indiciam uma imersão significativa do social-histórico no universo simbólico peculiar (embora não exclusivo) das redes.

\subsection{Smart cities e imaginário utópico Grande Glocal}

As características de base das smart cities fazem per se relevante a contextualização social-histórica peculiar de seu aparecimento, no estirão dos padrões teleológicos 
ocidentais, para situá-las no estrato movediço das placas tectônicas do imaginário social da "vida humana perfeita" e, num único voleio, apreender a reeescritura epocal radical do tecido utópico da civilização mediática.

No rastro dos últimos dois séculos e meio, a cultura ocidental vive, desde o final do século XX, transição de prioridade no que se refere ao investimento de energias em narrativas projetadas para o futuro. As utopias tradicionais e socioespacializadas na ucronia universal do tempo vindouro, na circunscrição de uma sociedade alternativa ao status quo gestada e previamente incrustada no imaginário social e que vanguardas e massas militantes envidaram lutas em série (algumas exitosas, outras em vão) para concretizar, de modo estável e seguro, a história mais recente da vida urbana, em imanente conexão com os resultados eletrônico-domésticos da tecnociência, testemunharam a emergência de utopias tecnológicas parcelares e localizadas, microssociais e corporais, conforme farta descrição feita por Sfez (1996; cf. também TRIVINHO, 1999, Parte II, Cap. VIII). Em termos contextualizados (alinhados exclusivamente à temática do presente estudo), a cultura ocidental observa, em curto lapso de tempo (a partir do fim da Segunda Guerra Mundial), a passagem significativa (e ainda pouco estudada com a devida profundidade) das macroteleologias convencionais (desde o humanismo greco-clássico até todos os "ismos" modernos, de direita e de esquerda, no registro tanto político-econômico, quanto religioso e filosófico: iluminismo, liberalismo, marxismo, anarquismo etc.) para as sociotecnoteleologias forjadas em projetos científico-laboratoriais específicos, todos de dotação bilionária, na direção de circunscrições urbanas diminutas, aparentemente desidratadas da sanha totalizante de suas congêneres historicamente precedentes.

Apenas para sucinto recenseamento, enquadram-se nesse arco de reescrita tecnocientífica da lógica ocidental dos telos - vale dizer, de inoculação do interesse imaginário-teleológico em concepções científicas de ponta - ao menos, cinco neo-utopias, todas de natureza empíreo-construtivista: a da eugenia biotecnológica (da "saúde perfeita", segundo Sfez, conforme abaixo), a da clonagem, a da descoberta alien, a da transferência da humanidade para outro planeta e a do Grande Glocal.

A neo-utopia da eugenia biocibertecnológica anima-se, segundo Sfez, a partir de três projetos científicos avançados, desencadeados no final do século XX:

a. o Human Genome Project (Projeto Genoma Humano, de envergadura mundial), voltado para o mapeamento e sequenciamento total do genoma humano, incluindo expurgo de genes "defeituosos" e otimização dos demais; e, a partir disso - no limite -, para "purificação" e aperfeiçoamento do corpo, do environment e da orbe terrestre;

b. a Biosphere Two, que bancou, em gigantescos hangares no deserto do Arizona, nos Estados Unidos, no início dos anos 1990, experiências com biomas humanos e espécies animais e vegetais, com o objetivo de alcançar a assepsia de Biosfera I (a da vida humana até o momento); e 
c. a Artificial Life (Vida Artificial), programa radical do Santa Fé Institute, da Universidade da Califórnia, nos Estados Unidos, para conduzir às últimas consequências o estrato robótico das cibertecnologias, especialmente a Artificial Inteligence (AI), capacitando-a para engendrar uma nova alteridade, historicamente inédita, o "sujeito" cyborg (cybernetic organism), efeméride humano-máquina, parte carne, parte artefato, com "consciência" de si e de mundo, a princípio unissex (porém não assexuado) e "autorreprodutor" (de outros "seres" idênticos, por transferência de tecnologia), com padrão de saúde incomparável - imune às mazelas da biosfera filogeneticamente legada - e com alta taxa de interação com seres humanos e animais, outros cyborgs e/ ou sistemas maquínicos.

Em alinhamento a estes projetos eugênico-ciberecológicos, embora não necessariamente conjuminada a eles, comparece, por sua vez, a neo-utopia da clonagem de animais e seres humanos, destinada, do ponto de vista de seu telos pressuposto, a "fundar" igualmente na história uma nova alteridade, orgânica em tudo, porém egressa de reprodução heterodoxa em relação tanto a esquemas genéticos da espécie, quanto a processos de inseminação artificial em curso. A ponta teleológica extrema dessa busca laboratorial da saúde idealizada para gerar uma "versão orgânica" supostamente "superior", sem os "senões" do "original" de referência, testemunha, por córregos científicos só aparentemente paralelos - eis que epocal e culturalmente consonantes -, a transferência, por métodos tecnológicos avançados, da humanidade para outros planetas, afã de vão delírio inscrito já no mencionado Projeto Biosfera II, com o objetivo de garantir, no limite, margens de retaguarda para a imortalidade da espécie humana (como "invenção natural"), na continuidade das tentativas obstinadas de reversão do esquema entrópico da vida, mediante golpe tecnocientífico de morte no drama da finitude, fronteira antes inultrapassável - tudo isso se ou para quando a Terra se tornar completa e realmente inabitável (seja por biodegradabilidade ou esgotamento de recursos naturais, seja por catástrofes imprevistas ou flagelo nuclear mundializado) (SFEZ, 1996, p. 26, 260]. ${ }^{3}$

3 Segundo Sfez (1996), essas cinco microutopias tecnocientíficas integram o perfil da emergente ecobiorreligião da (por ele chamada de) "Grande Saúde", entrefincada na biologia molecular, na engenharia genética e na ecologia e acossada pela velha ideologia da perfeição (de feitio sempre preconceituoso, no silencioso terreno dos pressupostos), com todas as consequências sociopolítica e juridicamente periclitantes em matéria de "eliminação legítima" potencial do que não lhe é identitário.

Não por outros motivos, tais micronarrativas conexas acumulam nas mãos dos contemporâneos, para além da política e da jurisprudência, inúmeros problemas antropológicos e sociais doravante enquadrados e questionados pela chamada bioethics ["bioética"], campo interdisciplinar de conhecimento que abrange recortes tecnocientíficos tanto tradicionais, como a experimentação com seres humanos (incluindo embriões), a reprodução assistida, os métodos contraceptivos, a inseminação e fecundação artificiais, o diagnóstico pré-natal, a transfusão de sangue e o transplante de órgãos; focos científicos de interesse mais recentes e não menos políticos e polêmicos, como os transgênicos, as células-tronco e a terapia genética, a eugenia, a distanásia e a eutanásia (inclusive fetal), a bioética feminista e a transexualidade; e problemas sociais de maior envergadura, como a política de contracepção, o direito ao aborto e ao suicídio, a aplicação da tortura (autorizada ou não) e da pena capital, e a poluição ambiental, entre outros - todos implicados na construção da humanidade futura. Em seleta, vejam-se, a respeito, Potter (1971, 2001), Muzur e Sass (2012) e Jonsen (1998); e, para ponderações e alternativas tensionais em relação ao modelo vigente de bioética como campo de conhecimento, indiquem-se Turner (2009) e Hedgecoe (2004). 
Pertence a idêntico horizonte visionário, talhando a matéria-prima da esperança trans-histórica com bisturi tecnocientífico sofisticado, a busca astrofísica norte-americana sistemática por alteridades exóticas (cf. GUILLAUME, 1989), mediante procedimentos de contato remoto com aliens, manutenção de estações interplanetárias, telemonitoramento de satélites superpotentes, possível colonização de Marte ou de outros planetas favoráveis à vida, entre outros recursos mobilizados. Esse radar, há tempos tão automatizado quanto incansável, envolve megainvestimentos de capital estatal e corporativo voltados para condicionar, na história, o "inteiramente outro" em versão jamais imaginada, boom insuperável sob o crivo da inteligência tecnocientífica - equivalente a "furo" devastador de reportagem, de longo efeito, no jargão da tradição jornalística -, uma "descoberta" inédita e revolucionária, com impacto em futuro eterno a partir de então, vergada sobre (o "fazer surgir" do umbral do desconhecido) um tipo de "ser" jamais testemunhado, capaz de atrair em bloco e indefinidamente nossa atenção (a especializada e a mediática) como seres humanos e, ao mesmo tempo, de assacar a humanidade de sua trajetória milenar "solitário-celibatária" (ibidem), na qual humanos têm interagido apenas com outros humanos e, quando não diretamente com sistemas de máquinas e agentes robóticos de redes interativas, se utilizado destes (como mediações) para se relacionar uns com os outros, de modo síncrono ou não. A esperança alien é a expressão instrumental do forte "desejo racionalizado" (e, por isso, convertido em utopia) de, ao fazer o gênero humano redimir-se dessa solidão antropológica (ibidem), promover no amanhã uma interação com um "ente inteligente" que, ao mesmo tempo, consagre, em retorno - de maneira até agora jamais vista - a validade histórica e ética bilionária da tortuosa trajetória tecnocientífica militarmente responsável pela catástrofe das próprias utopias tradicionais e modernas, em duas longas e recentes guerras mundiais, para não se registrar a continuidade da matança em massa, ano após ano, de modo mais rápido e fácil, em conflitos tecnológicos e químicos localizados, sem testemunho de sangue derramado (caso em que a matança é, por exemplo, levada a cabo por ataques aéreos, hoje capitaneados por aviões não tripulados e drones).

Aplainando, sem esgotar-se a matéria, o idiossincrático arco de telos egressos da desgraça pública das metanarrativas ocidentais tradicionais (cf. LYOTARD, 1986, 1993), sobreleva-se a neo-utopia comunicacional do Grande Glocal, a tendência sociofenomenológica e autopoiética de articulação de todos os principais rincões do planeta sob os auspícios da infraestrutura estendida de tecnologias e redes capazes de tempo real (de massa, interativa e/ou híbrida) e sob o influxo incessante de hábitos e práticas cotidianos em torno delas, com elas e a partir delas. Trata-se de um tecnotelos consuetudinário, isto é, sem discurso legitimatório acompanhante (de tipo seja normativo, seja especulativo), antes cumprido ao modo direto e diuturno, simultaneamente ao próprio desenvolvimento das práticas sociais articuladas em rede, dispensando a necessidade de ação justificatória sobre a sua própria validade social-histórica. ${ }^{4}$

4 O conceito de Grande Glocal cedo demonstra, no plano do significante (unicamente), similaridade não proposital com (e, portanto, distante da) "Grande Saúde", conforme a já mencionada proposição de Sfez (1996), de inspiração nietzscheana. 
Nutrindo-se de cada pressão em microbotões de controle remoto e console, cada acesso a redes comunicacionais, cada opção de click em telas, cada post atuado em contexto online (para citar exemplos apenas do estirão digital e interativo da civilização mediática) - enfim, cada cedência voluntária à intensa atração para a roda-viva das ações e reações mediaticamente síncronas, a neo-utopia do Grande Glocal ruma utilitariamente para a fase ômega da glocalização integral do planeta através da apropriação e utilização social de algum tipo de media em tempo real (aqui tomados em arco completo, incluindo os media eletrônicos de massa), vale dizer, mediante "relação (hedônica) com" aparelhos de rádio e TV (fixos ou móveis) e senhas infotécnicas de acesso à Web e seus múltiplos contextos (sites, blogosfera, "redes sociais", games etc.), como personal computers, celulares/smartphones, laptops, tablets e outros devices capazes de articular instantaneamente local e global em processo único, não redutível a seus dois constituintes.

Implicada na estruturação dinâmica e na modulação epocal de processos de vida em todos os domínios possíveis (da esfera do trabalho ao universo do lazer e do tempo livre), a sociofenomenologia dessa pragmática teleológica se expande diariamente na direção do atingimento de uma condição social-histórica em que todos os elementos existentes -indivíduos, lugares, interações e objetos (passíveis de "acolher" dispositivos de rede em tempo real) - estejam plenamente indexados (sem escape) pelo processo de glocalização, hoje "medida" referencial da "vida normal" (enredada, "naturalmente"), e, como tais, vigorem como caudatários e "bons condutores" estruturais [para evocar Baudrillard (1985)] da sociodromocracia imagético-informacional generalizada.

Tais características basilares, ensejando, no todo, uma dromocracia multimediática - de que a dromocracia cibercultural constitui a fase multicapitalista mais avançada (cf. TRIVINHO, 2007), com fincamento no cyberspace como pluriespacialidade interativa, com sua lógica online e streaming, e em recursos de GPS, sua ponta socioempírica de mobilidade up-to-date-, logo testemunham o quanto o Grande Glocal, nutrindo-se de cada rede em tempo real sem se reduzir a nenhuma, não deixa de representar e materializar, de certa forma - hic et nunc -, o idílico desejo milenar de liberação (aqui relativa) da materialidade objetal da existência e das corporalidades convencionais em prol da imaterialidade dos espectros mediáticos (cf. VIRILIO, 1995; GUILLAUME, 1989; TRIVINHO, 1999, Parte II, Cap. VIII), locus-fluxo heterodoxo de processamento social de "objetos" imagéticos, gráficos, textuais, sonoros e/ou audiovisuais - o mundo, na profundidade de seu peso, então convertido na horizontalidade-écran dos signos mediadegradáveis.

Projeto Genoma, assepsia de bios na troposfera, cyborg longevo (cabal ou parcial), clonagem, busca por aliens, transferência interplanetária e, de certa forma, até a glocalização mundializada, entre outras fantasias construtivistas (de grupos específicos ou coletivo-consuetudinárias) - são, no conjunto, direta ou indiretamente, figuras pertencentes ao "pós-humano", enfeixe teleológico de patamar metanarrativo reenquadrador das demais neo-utopias, capaz de, seja pela eugenia biocibertecnológica, seja por vias não conexas 
a ela, lançar luz complementar às tendências do imaginário social contemporâneo. Esse

"pacote" epocal, de viés tecnocientífico e/ou sociocibernético, sem descarte do húmus metafísico-prometéico há muito conhecido, alinha-se, para enfatizar o argumento de Sfez, ao elixir também milenar da perfeição: corpo "infalível", environmental oasis totalmente artificializado, fluidez eletromagnética (na menor resistência física), a da semiosfera de dinâmica instantânea, mediasfera de sedutor imediatismo - algo assim como vida genuinamente plena, jamais equivalente à sua corruptela.

\subsubsection{Transição de padrões imaginários: das utopias tradicionais às sociodromoteleologias}

O excurso anterior demonstra suficientemente que, depois da epopeia históricocultural das utopias convencionais exclusivamente territorializadas, desenvolvimentos mais avançados da tecnociência - dos laboratórios hospitalares e farmacêuticos ao campo bélico, do complexo de engenharias (incluindo a genética) ao universo multicorporativo (nos segmentos industrial, comercial e não-lucrativo), do domo semioglocalizado às vias públicas, cujos fluxos são doravante reescritos por instrumentação à base GPS e por briefings jornalísticos sobre as condições de trânsito - condicionaram a gloriosa vez, tão bem-sucedida comercialmente (até agora) quanto aparentemente irreversível, da tecnoutopia planetária de concretude imaterial a céu aberto, na forma-fluxo do Grande Glocal, no estrato da (ou com base na) cibergeografia espectral da informatização integral da sociedade. O imaginário tecnológico ocidental assim solicitou, com portento fenomênico, entrada histórica - by purchasing one-way ticket - no universo alfandegário satelitizado da informação imediata, a qual atravessa, hoje, robusta e fluentemente, sobretudo media móveis miniaturizados (como próteses corporais, de alta portabilidade), em especial com função GPS, há tempos com circulação profusa, na mão de todas as gentes, incluindo as das categorias sociais e profissionais desprestigiadas, e abertos a modos diversos de usabilidade.

O arrazoado sobre essa mutação de padrões macronarrativos socioutópicos, com o consequente deslocamento de poder de efetivação entre eles, pode ser reexpresso em argumentação alternativa, na esteira particular da neo-utopia cyberspace (cf. TRIVINHO, 1999, Parte II, Cap. VIII). A descrença pública e progressiva nas metanarrativas socioespacializantes desde que as utopias derivadas da ratio técnica e prometéica dos séculos XVI-XVIII até o século XX mundializado - a saber, o iluminismo francês e o liberalismo inglês, vigas do capitalismo; o socialismo real (SOREX), pilar da burocracia soviética e de seus países alinhados, da Europa oriental à Ásia, mais Caribe; e o nazismo, assecla discursivo do Terceiro Reich - conflagraram-se em dois longos quadriênios de barbárie protagonizada justamente pelo uso militarista da técnica e da tecnologia (recursos até então previstos na fantasia ideológica do progresso para liberar, pacífica e 
paulatinamente, a espécie humana de todos os tipos de dura e injusta labuta, de flagelos e obscurantismos, sejam materiais, sejam espirituais) acabou por figurar como viga lastradora da validade histórica do deslizamento da esperança utópica para o universo das sociodromoteleologias, na forma geopolítica estrutural de cidades-tempo, no sentido atual e sofisticado de contextos urbanos totalmente ciberdromocratizados, com a maioria dos processos estratégicos (empíricos e funcionais) realizados sob o princípio da produtividade da interação com máquinas e sistemas especializados à base de informação em tempo real. ${ }^{5}$ Em termos ainda mais contextualizados ao presente estudo, desde Utopia, de Thomas Morus, e La città del sole [A cidade do sol], de Tommaso Campanella, trazidas respectivamente à luz em 1516 e 1602, até as smart cities do século XXI, observa-se, a partir do miolo narrativo das especulações reconstrutoras do mundo, a transição de um imaginário social centrado na materialidade da vida local para um imaginário socioglocalista, interessado em (continuar a) situar a vida humana na imaterialidade das redes interativas, ela mesma embrenhada, de maneira inextricável, na infinda miríade de objetos e instrumentos físicos, eletrônicos ou não.

Não constitui equívoco alegar que a marca divisória fundamental entre os dois mencionados padrões metanarrativos é o fenômeno glocal e seu processo derivativo, a glocalização, bem como a dromocratização generalizada dos fluxos imagético-informacionais.

\subsubsection{Smart cities e reprodução dromoutópica da civilização glocal}

Socioconformação up-to-date do referido húmus metafísico-prometéico de projeção da vida humana com menor taxa possível de "defeitos" ou "resistências" - vale sublinhar, de tudo o que não é admitido na severa contabilidade do desejo epocal de perfeição -, as smart cities são, nessa direção, a reinvenção glocal e dromocrática do capitalismo ecologicamente cerzido nas e/ou com respaldo nas redes de comunicação e informação em tempo real. Tout court, as smart cities, em vista da infraestrutura tecnológica em tempo real de que dependem para existir e funcionar, dispõem-se historicamente na linhagem dromoutópica do Grande Glocal. Validando-se o argumento em sentido inverso, a glocalização planetária, na frequência da busca pós-industrial pelo Grande Glocal, e a dromocratização informacional generalizada, no horizonte do produtivismo de todas as práticas laborais e de lazer, são recursos instrumentalizados para a realização do imaginário das smart cities como nova panaceia teleológica. Preserva estrita equivalência sinalizar, na raiz desse perímetro sociofenomenológico buliçoso, que o glocal e seu autoperfilamento veloz permitiram o parto social-histórico da neo-utopia das smart cities.

5 Do ponto de vista da história social das ideias ligadas, desde o seu nascedouro, à organização do futuro da vida humana, a neo-utopia do Grande Glocal se esgueira, de forma imanente e direta, no progresso alinear da cibernética tal como proposta por Wiener (1968, 1985), a saber, como narrativa ideológica e utópica, a da comunicação. Vejam-se também Breton e Proulx (1991) e Breton (1992). 
Desse ponto de vista - o do social-histórico -, é possível entrever, com efeito, nos lados conexos desse processo unificado, o enraizamento mais profundo e as franjas de maior compromisso fenomênico-teleológico das smart cities: obedecendo, elas mesmas, a uma inflexão sociotecnológica (doravante autopoiética) de teleoglocalização multilateral de todas as "coisas" possíveis [implicadas, por seu turno, no "funcionamento inteligente" das interações sociais e no atingimento eficiente de resultados em prazos ultracurtos], as smart cities equivalem, no todo, a uma concretização histórica socioespacializada de sistemas tecnodromocráticos harmonicamente coincidentes com o Grande Glocal. Sob esse ângulo, os projetos de smart cities - dos socialmente majoritários e complexos aos mais segmentados ou de aplicação setorial - não deixam de vigorar como uma sorte não-planejada de experiência "sociolaboratorial" aberta e destinada, no terreno silencioso dos pressupostos operacionais, a legitimar a reprodução social-histórica alongada da civilização glocal.

A essa rota teleoaleatória pertence, evidentemente, a banalização da tensa convivência entre, por um lado, o hiperconcurso de sistemas maquínicos satelitizados (automatização avançada, com equipamentos interagindo com equipamentos, sistemas especialistas trocando dados com sistemas especialistas) e, por outro lado, a sub-utilização de recursos humanos (desemprego tecnológico, com deslocamento fortemente hierarquizado da força de trabalho para âmbitos de administração, gerenciamento e/ou execução, de monitoramento/controle e de preservação técnica/ asseio ambiente). Esse apontamento inspira rememoração retroativa à época inaugural da cibernética, na década de 1940. A visão de Wiener (1968, 1985), a qual nunca teve nada a ver com algo assim como uma "civilização Web" ou uma "civilização das redes sociais", pode, na base, ligar-se, mais profundamente, à ideia de smart cities. O ufano imaginário cibernético da relação humano-máquina e da automação, redivivo na década de 1970, com menos trabalho prático-braçal e mais tempo livre para todos, reatualiza-se também hoje na nomenclatura dessas cidades tecnológicas (mesmo se desprovidas de simetria setorial interna). Seja como for, prevalece este importante aspecto, na esteira da noção de cidadestempo: já não se trata mais tanto de espaço urbano, mas de puro estrato cronogeográfico de acesso e partilha de informação instantânea, socioesfera hipervolatilizada em redes interativas, na forma de uma "realidade ampliada", local e global ao mesmo tempo e, por isso, em tudo para além de ambos, em sua terceira dimensão já unificada no presente - uma condição glocal (TRIVINHO, 2007, p. 237-331, 2012, 2014, p. 25-50) no tecido da própria dromovisibilidade mediática, permitida por infraestrutura pesada e espalhada [e, no entanto, marcada por impressionante leveza processual (LIPOVETSKY, 2016, esp. p. 19-32) e pela apropriação e utilização diuturnas de tecnologias miniaturizadas por parte de praticamente todas as camadas da população.

Com tais características, que lhes esculpem o perfil de reconstrução sociocultural e político-econômica do espaço urbano, as smart cities não nomeiam senão, no atacado, o modo pelo qual a trama antropológica da esperança fundamentalista da história 
ocidental se refaz na cibercultura, aqui tomada - não será demais lembrá-lo - como a fase avançada (digital e interativa) do capitalismo herdado da modernidade industrial. Configuração robusta do telos na atualidade, as smart cities constituem, assim, o último refúgio histórico - quer dizer, mais recente - do imaginário tecnoutópico contemporâneo, aquele que, desde ao menos o final do século XVIII, nos encanta, nos envolve e, não raro, nos engana, doravante sem sangue derramado, mas também sem resolução histórica do sofrimento por parte de todos que, em extensa massa, são excluídos ou segregados do umbral dos vetores desse futuro anunciado.

Eugênio Trivinho é professor da PUC-SP, Coordenador Geral do CENCIB - Centro Interdisciplinar de Pesquisas em Comunicação e Cibercultura e Pesquisador do CNPq. eugeniotrivinho@uol.com.br

\section{Referências}

BAUDRILLARD, J. À sombra das maiorias silenciosas: o fim do social e o surgimento das massas. São Paulo: Brasiliense, 1985.

BRETON, P.; PROULX, S. L'explosion de la communication: la naissance d'une nouvelle idéologie. Paris; Montreal: La Découverte; Boréal, 1991.

BRETON, P. A utopia da comunicação. Lisboa: Instituto Piaget, s.d. [original francês: 1992].

CASTORIADIS, C. A instituição imaginária da sociedade. Tradução de Guy Reynaud. 2. ed. Rio de Janeiro: Paz e Terra, 1982.

GUILLAUME, M. La contagion des passions: essai sur l'exotisme intérieur. Paris: Plon, 1989.

HEDGECOE, A. M. Critical bioethics: beyond the social science critique of applied Ethics. Bioethics, SHERPA/HoMEO, v. 18, n. 2, p. 120-143, May 2004.

JONSEN, A. R. The birth of bioethics. Oxford; New York: Oxford University Press, 1998.

LIPOVETSKY, G. Da leveza: rumo a uma civilização sem peso. Barueri: Manole, 2016.

LYOTARD, J-F. O pós-moderno. Rio de Janeiro: José Olympio, 1986.

O pós-moderno explicado às crianças. Lisboa: Dom Quixote, 1993.

MUZUR, A.; SASS, H-M. (Ed.). Fritz Jahr and the foundations of global bioethics: the future of integrative bioethics. Zürich; Berlin: LIT Verlag, 2012.

POTTER, V. R. Bioethics: bridge to the future. Englewood Cliffs: Prentice-Hall, 1971.

. Moving the culture toward more vivid utopias with survival as the goal. Global bioethics, United Kindom, v. 14, n. 4, p. 19-30, 2001. Disponível em: http://www.tandfonline.com/doi/pdf/10 .1080/11287462.2001.10800810. Acesso em: 19 jul. 2020.

SFEZ, L. A saúde perfeita: crítica de uma nova utopia. São Paulo: Unimarco, Loyola, 1996.

TRIVINHO, E. Cyberspace: crítica da nova comunicação. São Paulo: Biblioteca da ECA/USP, 1999. 466p. 
A dromocracia cibercultural: lógica da vida humana na civilização mediática avançada. São Paulo: Paulus, 2007.

Glocal: visibilidade mediática, imaginário bunker e existência em tempo real. São Paulo: Annablume, 2012.

A condição glocal: configurações tecnoculturais, sociopolíticas e econômico-financeiras na civilização mediática avançada. São Paulo: Annablume, FAPESP, 2014.

TURNER, L. Anthropological and sociological critiques of bioethics. Journal of Bioethical Inquiry, Netherlands, Springer, v. 6, n. 1, p. 83-98, Mar. 2009.

VIRILIO, P. La vitesse de libération. Paris: Galilée, 1995.

A arte do motor. São Paulo: Estação Liberdade, 1996.

WIENER, N. Cibernética e sociedade: o uso humano de seres humanos. 15. ed. São Paulo: Cultrix, 1968.

Cybernetics. Cambridge, MA, MIT Press, 1985.

Artigo recebido em 30/05/2020

e aprovado em 25/07/2020. 